\title{
Formação continuada de professores e educação antirracista: ensino de história, africanidades e rompimento de estereotipias
}

\author{
History Teaching, Africanities and Disruption \\ of Stereotypes in Anti-Racist Teacher Training
}

Tanara Forte Furtado*

Carla Beatriz Meinerz ${ }^{*}$

\section{Resumo}

$\mathrm{O}$ artigo tematiza impactos do estudo das Africanidades na formação continuada de docentes, no Curso de Aperfeiçoamento Uniafro/UFRGS, que atuam na educação infantil e nos anos iniciais do ensino fundamental. Compartilha considerações de estudo em andamento, na área da pesquisa em Educação, articuladas no objetivo de compreender a implementação do ensino de história afro-brasileira como ação afirmativa no campo do currículo. Os resultados parciais demonstram a existência de processos de construção de estereotipias e de desestabilização de subjetividades docentes, na consolidação da Educação das Relações Étnico-Raciais nos espaços escolares. São referências analíticas as pensadoras Azoilda Loretto da Trindade, Nilma Lino Gomes e Petronilha Beatriz Gonçalves e Silva.

Palavras-chave: ensino de história; história afro-brasileira; educação infantil.

\section{Abstract}

The article discusses the impacts of the study of Africanities in the continuing education of teachers, in the Uniafro / UFRGS Improvement Course, who work in early childhood education and in the early years of elementary school. It shares ongoing study considerations in the area of research in Education, articulated with the aim of understanding the implementation of Afro-Brazilian history teaching as an affirmative curricular action. The partial results demonstrate the existence of construction processes of stereotypes and destabilization of teaching subjectivities, in the consolidation of the Education of Ethnic-Racial Relations in school spaces. Analytical references are the thinkers Azoilda Loretto da Trindade, Nilma Lino Gomes and Petronilha Beatriz Gonçalves e Silva.

Keywords: history teaching; afro-brazilian history; child education.

\footnotetext{
* Universidade Federal do Rio Grande do Sul (UFRGS), Porto Alegre, RS, Brasil. tanara.forte. furtado@gmail.com

** Universidade Federal do Rio Grande do Sul (UFRGS), Porto Alegre, RS, Brasil. carlameinerz@ gmail.com
} 


\section{HORIZONTE INICIAL: AFRICANIDADES}

E VALORES CIVILIZATÓRIOS AFRO-BRASILEIROS

Em vez de nos deixar paralisar pelas concepções que nos despotencializam, redescobrimos os Valores Civilizatórios Afro-brasileiros.

(Trindade, 2010, p. 13)

O encontro com as Africanidades e os Valores Civilizatórios Afro-brasileiros, como alternativa educacional e epistemológica para o ensino de história afro-brasileira, inspira a análise teórica aqui empreendida, cujo foco temático é o combate ao racismo em ações de formação continuada com professores da educação básica no sul do Brasil. Tal encontro permite a contemplação, junto às crianças, de um outro jeito de se relacionar socialmente, a partir de ideais como a cooperação e a coletividade. Instiga a reflexão sobre a função social do ensino de História, como parte da construção de projetos educativos e humanitários.

Analisamos registros de criação e aplicação de atividades pedagógicas na educação infantil e anos iniciais, com base em noção de positividade na narrativa acerca da história afro-brasileira, com a multiplicidade de vivências elaboradas por pessoas e comunidades negras de nosso país. Os relatos são efetuados por docentes de escolas públicas (rede estadual e redes municipais) do Rio Grande do Sul, formados no Curso de Aperfeiçoamento UNIAFRO/Política de Promoção da Igualdade Racial, promovido pela Universidade Federal do Rio Grande do Sul (UFRGS) nos anos de 2013 e 2014. O curso, ofertado na modalidade semipresencial, contou com 210h/a distribuídas em 7 (sete) módulos, por meio dos quais os/as docentes foram convidados/as a refletirem sobre 4 temas específicos: história da escolarização do povo negro no Brasil; território, educação e significações etnoculturais; africanidades brasileiras e promoção de ambiência para a igualdade racial na escola; e corpo e diferença racial na educação escolar). Do total de 370 docentes participantes, 58 autodeclararam-se negros/as (15,6\%), sendo 343 mulheres (92,7\%) e 27 homens (7,3\%), com faixa etária entre 22 e 50 anos. Após a leitura e discussão do texto-base teórico de cada módulo, as cursistas participaram de um fórum assíncrono de discussão, bem como realizaram e registraram atividades pedagógicas 
junto às suas turmas da educação básica. São estes registros que compõem o acervo analisado neste artigo.

Os dados observados apontam processos de construção de estereotipias e de desestabilização de subjetividades, desenvolvidos em experiências de ensino de história afro-brasileira na educação infantil e nos anos iniciais do ensino fundamental - etapas da educação básica em que são atendidas crianças entre 4 e 10 anos.

As práticas de ensino em geral, e da História em específico, necessitam considerações acerca das importantes mudanças nos aspectos cognitivos, afetivos e sociais instaurados pela gradual ampliação da capacidade de interação grupal e de construção de representações simbólicas, no concernente à atribuição de significados à realidade. Tais capacidades se desenvolvem na medida da ação e da relação com o mundo, do vivido que vai igualmente se elaborando na qualidade de concebido ou abstraído. O ensino de história atua nesse interstício de experimentações vitais, construindo-se nas disputas por formas de narrar as transformações que atravessam e aproximam passado e presente, para homens e mulheres de distintos tempos e espaços. A perspectiva das Africanidades contribui para expressar que não existe um único jeito de viver e significar o mundo, afirmando que "o universo é gerado na existência coletiva, prevalecendo o Ser Humano e o Espaço enquanto expressão da chamada força vital” (Santana, 2006).

Azoilda Loretto da Trindade (2010) escreve sobre o desafio de "educar pela vida e para a vida", através dos valores civilizatórios por ela concebidos a partir de uma afro-brasilidade expressa em "maneiras, possibilidades de matrizes africanas ressignificadas pelo modo de ser dos brasileiros/as" (2010, p.13). Para a educadora, as crianças, particularmente na educação infantil, têm direito a se conectar com a existência de outros modos de ser, fazer, brincar e interagir que não os hegemônicos no mundo euro-norte-centrado, masculino, branco, burguês, monoteísta, heterossexual e hierarquizado. Valores que imprimem outro projeto de humanidade, outro modelo de civilização, são aqui denominados como "valores civilizatórios de matriz africana à nossa brasilidade que é plural" (2010, p.13). A ação de ensinar história pode explicitar os valores civilizatórios que pautam suas escolhas metodológicas e epistemológicas.

Diante das especificidades da construção do pensamento infantil, torna-se demasiado difícil a tarefa de ensinar a uma criança algo que esteja completa- 
mente fora do seu horizonte mais imediato de experimentações. É preciso cheirar, olhar, tocar, ouvir e até mesmo degustar, literalmente, aquilo que se pretende tornar conhecido, familiar. É através do corpo - pelo seu próprio e pela relação com a corporeidade dos outros - que os pequenos aprendem sobre si e sobre os demais. Essas vivências podem ocorrer num processo de aprendizagem que varia conforme as visões compartilhadas do mundo adulto em que se desenvolvem, no caso da sociedade brasileira, um mundo no qual o racismo opera cotidianamente nas estruturas pessoais e institucionais. A escola, portanto, como instituição, tende a reproduzir atitudes de preconceito e de discriminação racial. O próprio ensino de História, ao longo de séculos, priorizou centralizar as narrativas no projeto civilizatório colonialista e europeu, implementado através dos crimes de escravidão, reproduzindo histórias mínimas e estereotipadas acerca dos povos originários da América e dos povos africanos que migraram forçosamente para o Brasil.

Nesse contexto, o conceito de Africanidades Brasileiras se apresenta enquanto concepção indispensável para as práticas pedagógicas que objetivem a promoção do conhecimento e reconhecimento das agências da população negra brasileira no transcorrer dos tempos e na contemporaneidade. Trata-se de práticas que, por estarem comprometidas com o projeto da Educação das Relações Étnico-Raciais (ERER), não desestabilizam apenas o currículo no que diz respeito ao conteúdo histórico a ser estudado, mas também à atitude ensinada, pois exigem uma posição ética e política diante das relações racistas e racializadas no cotidiano escolar.

Como concebemos as Africanidades Brasileiras em práticas pedagógicas de ensino de História com crianças? Seria ilusão imaginar que se trata apenas de apresentar às crianças um diversificado catálogo de pratos gastronômicos, sambas-enredo famosos ou mesmo exercícios de capoeira na aula de Educação Física. Não queremos reificar estereotipias ou cristalizar subjetividades únicas em parcelas da população brasileira, destacadamente pessoas negras e indígenas.

Defendemos a perspectiva da brasilidade plural, herdeira consciente e reconhecida dos Valores Civilizatórios Afro-brasileiros que constituem experiências de inspirar atitudes éticas entre todos os seres vivos. Quais valores? Segundo Trindade (2010), Energia Vital, Circularidade, Corporeidade, Memória, Ancestralidade, Territorialidade, Religiosidade, Cooperação, Comunitarismo, Oralidade, Musicalidade e Ludicidade são os elementos fundamentais 
desse panteão ético construído na experiência da diáspora africana no Brasil. Para a educadora, "a energia vital é circular e se materializa nos corpos, não só nos humanos, mas nos seres vivos em geral, nos reinos animal, vegetal e mineral" (Trindade, 2010, p. 14). Que impactos isso tem para a formação docente no campo do ensino da história afro-brasileira?

De acordo com Petronilha Beatriz Gonçalves e Silva (2005), para ensinar as Africanidades Brasileiras é preciso, antes de tudo, compreender que não estamos falando tão somente de uma disciplina curricular específica, mas sim de um campo de estudos caracterizado pela inter-relação de diferentes áreas de conhecimento, que toma como perspectiva a cultura e história dos povos africanos e seus descendentes. Essa perspectiva associa valores civilizatórios que por vezes conflitam com os cultuados em ambientes acadêmicos e escolares, como o individualismo, a competitividade, a hierarquia de saberes, a meritocracia e a centralidade na escrita.

É preciso contemplar tanto a dimensão processual de aquisição de um conjunto de conhecimentos quanto a formação de uma atitude respeitosa de reconhecimento e contribuição dos afro-brasileiros na sociedade brasileira (Silva, 2005). Por isso, reforçamos a dimensão relacional do ensino da história afro-brasileira na educação infantil.

Ao optarmos por uma ação pedagógica antirracista, necessitamos disposição atitudinal para combater nossos próprios preconceitos e nossas formas acomodadas de promovermos visões uniformes a respeito de pessoas e comunidades negras. Tal disposição nos encaminha para o reconhecimento de outros projetos de civilização e de humanidade, fundamentados em vivências partilhadas na diáspora afro-brasileira, capazes de ultrapassar o enlace que cataloga ou estereotipa práticas culturais inseridas no cotidiano da sociedade brasileira. Como afirma Silva (2005):

[...] todos nós comemos feijoada, cantamos e dançamos samba, e alguns frequentamos academia de capoeira. E isto, sem dúvidas, é influência africana. De fato o é, mas há que completar o pensamento, vislumbrando os múltiplos significados que impregnam cada uma destas manifestações. [...] Assim, uma receita de feijoada, vatapá, ou de qualquer outro prato, contém mais do que a combinação de ingredientes, é o retrato de busca de soluções para a manutenção da vida física, de lembrança dos sabores da terra de origem. [...] Africanidades Brasileiras ultrapassam, pois, o dado ou o evento material, como um prato de sarapatel, uma 
congada, uma apresentação de capoeira. Elas se constituem nos processos que geraram tais dados e eventos, hoje incorporados pela sociedade brasileira. Também se constituem nos valores que motivaram tais processos e dos que dele resultaram. (Silva, 2005, p. 155-156)

São valores como o comunitarismo e a cooperação que motivam a possibilidade de criação de uma roda de samba ou capoeira, resultantes dos agenciamentos de resistência afetiva e efetiva das pessoas negras em movimento constante e vital. Vejamos como esses valores foram propostos no curso Uniafro/UFRGS, igualmente como foram recebidos pelas professoras em formação, através de registros que demonstram enfrentamentos internos e externos em relação a preconceitos e discriminações raciais.

AFRICANIDADES COMO PRINCÍPIO NA FORMAÇÃO DOCENTE: DESAFIOS DO ROMPIMENTO DE ESTEREOTIPIAS NO ENSINO DE HISTÓRIA

Investigamos dados produzidos a partir da proposição didática do Módulo "Africanidades na sala de aula: a construção de uma ambiência racial na escola", da primeira e da segunda edição do Curso de Aperfeiçoamento UNIAFRO/UFRGS, ofertado pelo Centro de Formação Continuada de Professores da Universidade Federal do Rio Grande do Sul (Forprof/UFRGS) nos anos de 2013 e 2014, através de financiamento do Ministério da Educação (MEC) e do Fundo Nacional de Desenvolvimento da Educação (FNDE).

O curso, na modalidade semipresencial e com carga horária de 210 h/a, teve como público-alvo professores da educação básica das redes públicas de ensino do Estado do Rio Grande do Sul. O objetivo principal primou pela "qualificação da educação antirracista em curso nas escolas públicas do estado do Rio Grande do Sul, visando o atendimento da Lei 10.639/2003". Dentre os específicos, a "elaboração, implementação e avaliação de ações pedagógicas voltadas para a problematização do racismo a partir de artefatos culturais brinquedos, filmes, livros, telenovelas, mídia, dentre outros - e práticas culturais - convívio em clubes, praças, parques, templos, distribuição urbana territorial étnico-racial, dentre outras - nas cidades de atuação dos cursistas".

Os dados aqui compartilhados constituem-se de registros realizados por 210 professoras cursistas, cuja prática docente esteve distribuída entre os mu- 
nicípios de Agudo, Balneário Pinhal, Caxias do Sul, Jaguarão, Mostardas, Porto Alegre, Rosário do Sul, Santo Antônio da Patrulha, São Lourenço do Sul, Sapiranga e Vila Flores. As informações foram fornecidas enquanto instrumento avaliativo relacionado à proposição de prática pedagógica que deveria promover a apresentação de uma ambiência racial em que o negro fosse visibilizado de forma positivada e não estereotipada, conforme orientações das DCNERER (2004).

A proposição didática em análise realizou-se em cinco etapas:

1) Leitura de um texto-base produzido pela professora responsável pelo Módulo, Tanise Müller Ramos, intitulado "Africanidades na sala de aula: a construção de uma ambiência para a igualdade racial na escola”. O escrito destaca a necessidade premente de se pensar a escola como um espaço potente para a criação de uma ambiência racial afirmativa e pluriétnica, dando importância à representação da população negra brasileira e enfatizando o conceito de Africanidades Brasileiras para a implementação de propostas de educação para a igualdade racial. A definição de Africanidades, nesse Módulo, fundamenta-se nos estudos de Silva (2005), concernentes à influência africana nas manifestações culturais no Brasil, constituindo-se em valores, formas de vida, de trabalho, eventos, dados e demais processos empreendidos pelos descendentes de africanos e incorporados pela sociedade brasileira em seus diferentes grupos étnico-raciais.

2) Discussão coletiva em fórum on-line específico a partir da seguinte questão disparadora: "Como sua escola e também sua sala de aula poderiam proporcionar uma ambiência para a igualdade racial?”

3) Implementação de prática pedagógica, considerando adequação à idade e interesse dos alunos, de modo a garantir às crianças as referências de concretude material e simbólica indispensáveis aos processos cognitivos desta faixa etária, a citar os diferentes artefatos culturais (livros de literatura, filmes, animações, imagens de revistas, obras de arte, brinquedos, fotos, jogos). Tal prática deveria estar vinculada a alguma proposta ou projeto pedagógico anteriormente criado para este fim, com intenção de evitar uma ação descontextualizada.

4) Divulgação da ação realizada junto à comunidade escolar.

5) Postagem de uma produção textual no ambiente virtual de aprendizagem do curso, na qual constasse o relato evidenciado e reflexivo sobre o de- 
senvolvimento da proposta. Essa produção foi denominada como relatos no estudo, ora apresentado.

Além de garantir a inclusão dos conteúdos da história afro-brasileira no currículo escolar, cabe rever o equívoco de alterar o foco etnocêntrico europeu por outra abordagem ainda pautada pela branquitude (Bento, 2012), aquela que reitera estereotipias. Sem estereótipos, a proposta promove o conhecimento e o reconhecimento da capacidade da população negra brasileira de manter-se em luta e de reorganizar seus modos de ser e de viver, à luz das práticas culturais e dos valores civilizatórios africanos, ressignificados no contexto da diáspora.

Ao disponibilizar o processo de produção e análise dos registros, visamos à interpretação e problematização do conteúdo curricular relativo à história afro-brasileira, tangente a pautas sobre eurocentrismo e racismo, questionando o modelo colonialista, escravocrata e branco.

O objetivo central é compreender a maneira pela qual as 210 professoras cursistas conseguiram lançar mão do conceito de Africanidades Brasileiras, numa perspectiva de ensino de história afro-brasileira articulado à dimensão atitudinal da ERER.

Destacamos o termo quebra de desconfianças como pressuposto fundamental ligado à ERER e o emprestamos do Parecer do Conselho Nacional de Educação/Conselho Pleno (CNE/ CP) 03/2004, que aprova as DCNERER, cuja redação diz o seguinte:

A educação das relações étnico-raciais impõe aprendizagens entre brancos e negros, trocas de conhecimentos, quebra de desconfianças, projeto conjunto para construção de uma sociedade justa, igual, equânime. (Brasil, 2004, p. 6)

A ERER está radicalmente associada à ideia de quebra de desconfianças como estratégia de combate ao racismo e à discriminação racial no cotidiano escolar. A complexidade da recepção dessa proposição, nas ações para a formação continuada de docentes, desvela as tensões presentes na adoção de tal política afirmativa. São as tensões próprias das relações raciais vividas no Brasil. Articula-se, igualmente, com a adoção de pedagogias direcionadas para a positivação das histórias e culturas negras, com o objetivo de fortalecer entre os negros e despertar entre os brancos a consciência negra (Brasil, 2004). Tais estratégias resultam de demandas sociais construídas pelas pessoas negras no nosso país. 
Essa quebra de desconfianças exige ações ancoradas em princípios que considerem o ensino de história afro-brasileira capaz de descortinar a secular perversidade do preconceito, da discriminação racial e do racismo endereçados à população negra brasileira. Constitui potente ferramenta para a compreensão, problematização e superação das representações de supremacias ou estereotipias.

A educação antirracista no ensino de História possibilita a superação de práticas que conferem ao diferente alguns atributos ou imagens de inferioridade, negatividade e consequente menoridade social justificada. Stuart Hall (2016) convida a pensar a diferença a partir da representação racial, analisando imagens do negro na cultura ocidental e a correlata construção dos estereótipos, redutores, simplificadores ou essencialistas. A estereotipagem, segundo o autor, naturaliza e fixa o diferente, contribuindo para o enfraquecimento dos negros, infantilizados e fetichizados, ao mesmo tempo que fortalece os brancos em seus espaços de poder e privilégio. Cria-se, assim, uma estrutura binária da estereotipagem racial. Segundo Hall, a estereotipagem é uma prática capaz de contribuir para a persistência de estruturas mais profundas de representação racializada, responsáveis pela manutenção de desigualdades de poder.

No Dicionário de Ensino de História, produzido no contexto brasileiro, a definição de estereotipia também admite essa relação entre representações e práticas culturais, sistematizando que:

O estereótipo organiza o pensamento e as atitudes de modo a oferecer uma descrição, incipiente ou elaborada, acerca do mundo. Essa descrição, por sua vez, engendra formas de viver, de sentir e de agir pautadas, em geral, pela generalização (do grego - molde sólido) acerca do desconhecido, ou, para alguns - do outro. Nessa generalização pode-se construir ideias reguladoras capazes de sustentar práticas preconceituosas, discriminatórias, contrárias ao que chamamos de Direitos Humanos - cosmovisão de tradição europeia, ou Ubuntu - cosmovisão de tradição africana, ou Bem Viver - cosmovisão de tradição dos povos originários da América. (Meinerz, 2019, p. 102-103)

Não desejamos criar binarismos entre representações distintas das relações humanas, desejamos agregar práticas pedagógicas capazes de avançar no combate ao racismo que opera nas interações no nosso país. Parece que o Ubuntu, dentro do debate que ensejamos, pode enriquecer a reflexão no cam- 
po do ensino de História. Reiteramos que não se trata de manejo de conceitos com a mesma proposição, mas de conceitos com matrizes e valores civilizatórios distintos. O filósofo Fernando Noguera (2012) nos convida a pensar o Ubuntu como uma arte de viver em afroperspectiva. O termo afroperspectivista, para o autor, "tem um sentido simples, o conjunto de pontos de vista, estratégias, sistemas e modos de pensar e viver de matrizes africanas" (Noguera, 2012, 147). Não desejamos reduzir o Ubuntu a um conceito, mas destacar que sua compreensão pode tornar-se uma contribuição positiva e desestabilizadora para o ensino de História, ainda hegemonizado pela concepção de matrizes colonialistas e europeias. Ubuntu, palavra compartilhada gráfica e fonologicamente entre quatro grupos étnicos africanos (ndebele, swati, xhosa e zulu), pode ser uma possibilidade afroperspectivista para as relações das pessoas consigo e com as outras. Sua base está em práticas culturais coletivistas, comunitaristas, policêntricas e antirracistas.

Questionamos o reforço de generalizações em ações pedagógicas que agregam ideias reguladoras e homogeneizadoras sobre pessoas e comunidades negras, através de práticas dissociadas de valores, como o exemplo de uma apresentação isolada de capoeira, sem aprofundamento de conhecimentos e estudos das histórias dessa prática cultural considerada patrimônio histórico nacional.

Vejamos como as estereotipias aparecem nos dados aqui compilados e analisados. Todos os registros das cursistas passaram por uma leitura flutuante, com base na técnica da metodologia de análise de conteúdo (Bardin, 2011), e resultaram em dois núcleos de sentido estabelecidos a partir da ausência ou da presença de reflexões acerca da experiência vivida pelas professoras e pelas crianças nos ambientes escolares. Esses núcleos foram categorizados como rupturas (primeiro) e ausência de reflexões (segundo). No quadro abaixo é possível visualizar a distribuição dos registros de acordo com os núcleos de sentido estabelecidos.

O Quadro 1 demonstra que entre sessenta e setenta por cento das cursistas viveram alguma ruptura no seu processo de formação através do Curso em questão. Aos registros que evidenciaram reflexões foi atribuído o núcleo de sentido rupturas, vinculado à categoria rupturas com o racismo, por sua vez analisada em sua dimensão relacional, qual seja, a desestabilização das subjetividades das crianças e das professoras/cursistas, no que diz respeito às rela- 
ções inter-raciais. As rupturas com o racismo são compreendidas na lógica da aprendizagem como processo de desestabilização (Freire, 2018). Aos registros que não evidenciaram reflexões de nenhuma natureza foi atribuído o núcleo de sentido ausência de reflexões.

Quadro 1 - Quantitativo e percentual geral de registros da $1^{\text {a }}$ e $2^{\text {a }}$ edições de acordo com os núcleos de sentido

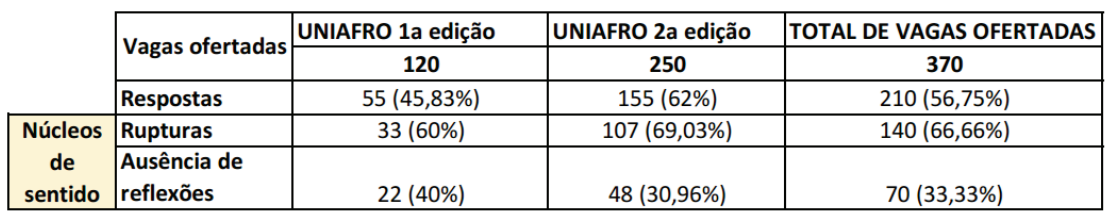

Fonte: elaborado pelas autoras.

Para fins deste texto, serão considerados apenas os registros inseridos na categoria rupturas com o racismo, causadas em processos de desestabilização de subjetividades e construção de quebra de desconfiança.

O conceito de subjetividade é compreendido a partir da referência guatarriana, que destaca suas dimensões plurais e polifônicas, desconhecendo "uma instância dominante de determinação que guie as outras instâncias segundo uma causalidade unívoca" (Guatarri, 1992). Em outras palavras, trata-se de uma concepção sobre a produção da identidade e personalidade, por meio de múltiplas experiências que vão se constituindo ao longo da trajetória dos sujeitos, de formas relacional, histórica e localmente contextualizadas. $\mathrm{Ou}$ seja, há uma tensão constante entre as situações e estruturas de processos de assujeitamentos sociais e as potencialidades de agência, de tomadas de posição, decisões e escolha. Essa referência dialoga com a ideia de uma brasilidade plural e da necessidade de incorporar os Valores Civilizatórios Afro-brasileiros nas narrativas de ensino da história do país.

Nilma Lino Gomes (2017) possibilita compreender a própria obrigatoriedade legal do ensino de história afro-brasileira como resultante das lutas emancipatórias e dos saberes desestabilizadores construídos pelas pessoas negras em movimento no Brasil.

O conceito de desestabilização das subjetividades tem inspiração na proposição de um projeto Educação 
[...] para o inconformismo, para um tipo de subjetividade que submete a uma hermenêutica de suspeita à repetição do presente, que recusa a trivialização do sofrimento e da opressão e veja neles o resultado de indesculpáveis opções. [...] Por isso, a sala de aula tem de transformar-se ela própria em campo de possibilidades de conhecimento dentro do qual há que optar. Optam os alunos tanto quanto os professores e as opções de uns e de outros não têm de coincidir nem são irreversíveis. As opções não assentam exclusivamente em ideias já que as ideias deixaram de ser desestabilizadoras no nosso tempo. Assentam igualmente em emoções, sentimentos, e paixões que conferem aos conteúdos curriculares sentidos inesgotáveis. (Santos, 1996, p. 17-18)

Os registros capazes de evidenciar dúvida, tristeza, angústia, desconforto, espanto, desaprovação, entusiasmo, alegria e esperança foram compreendidos como indícios de desacomodação das crianças e das professoras cursistas no que diz respeito aos seus modos de pensar e viver as questões étnico-raciais, tanto na dimensão dos conteúdos quanto das atitudes e valores.

No intuito de tornar fluida a compreensão dos resultados parciais do estudo, na sequência apresentaremos excertos das considerações interpretativas e analíticas.

\section{DesestabilizaÇão De SUbJeTIVIDAdes \\ DE SI E DO OUTRO: RUPTURAS COM O RACISMO}

Para a categorização das rupturas foram alocados os relatos que apresentam reflexões que ultrapassam o apontamento dos possíveis aprendizados de conteúdo por parte das crianças, tornando central os papéis das professoras e das escolas.

A solidão da ação docente antirracista no ambiente escolar é sentida como um obstáculo a ser vencido no percurso da implementação efetiva do ensino da história e da cultura africana e afro-brasileira. Desde a obrigatoriedade posta no artigo 26-A da Lei de Diretrizes e Bases da Educação Nacional, criado com a Lei 10.639/03, comprometem-se, às orientações constantes nas DCNERER (2004), alguns docentes listados em tais documentos (no exemplo abaixo, professores de História), negros ou simpatizantes da causa do combate ao racismo. Segundo um registro: 
Na verdade este trabalho na escola ainda é um tanto solitário, ou ele é dos professores de História, dos professores negros ou de uma minoria que se identifica com o assunto. Embora exista uma lei, poucos são os colegas que têm conhecimento dela e a colocam em prática. Poucos são os que se preocupam com a construção de uma ambiência racial na sala de aula, considerando as Africanidades (Cursista da 1a edição - Mulher).

Não bastasse o descaso dos colegas, também é preciso vencer a inércia das equipes gestoras que, além de não verificarem se o ensino está sendo garantido, sequer apoiam e garantem visibilidade às ações que estão sendo realizadas, segundo relatos compilados. $\mathrm{O}$ espaço e o tempo das reuniões pedagógicas precisam ser negociados, como se fosse uma espécie de favor a discussão da educação das relações étnico-raciais.

É preciso salientar que não houve nenhum apoio direto e nem incentivo da equipe diretiva. Era preciso insistir com as supervisoras para usar um pequeno espaço da reunião e, em geral, enquanto eu falava a minha supervisora não prestava atenção. Ela também não incentivou as colegas a participarem dos projetos sugeridos e, tampouco, fazerem os seus próprios. Ainda que no planejamento inicial, feito no início do ano, esteja contemplado esse objetivo. Em um dado momento, quando apresentei um projeto de uma feira envolvendo todas as turmas da escola, ela respondeu: Se for atrapalhar na entrega de todas as coisas que já solicitei a elas eu não vou deixar! Optei por usar os espaços que me concediam para divulgar a criação do Grupo de Ações Pedagógicas Afirmativas e motivar os professores a participarem do grupo e dos projetos que estávamos fazendo. Uma única professora me procurou. (Cursista da $2^{\mathrm{a}}$ edição - Mulher)

Além da indiferença, há registros de equipes gestoras que estranham o desenvolvimento de propostas voltadas para a educação das relações étnico-raciais fora da Semana da Consciência Negra:

O trabalho realizado foi desenvolvido em sala de aula e o painel confeccionado foi exposto no corredor da escola. As bonecas Abayomis foram presenteadas aos professores e os alunos dispuseram-se a fazer oficinas e ensinar os demais alunos, mas os professores não demonstraram interesse. Quanto à direção da escola, mostrou-se apenas "curiosa", pois eu desenvolvi o trabalho fora do projeto da "Semana da Consciência Negra", que a escola realiza em novembro. Pude 
perceber e vivenciar que a Lei 10.639 não é vivenciada e trabalhada nas escolas como deveria ser, pois apenas em final de novembro é que a questão da igualdade é lembrada e trabalhada por algumas disciplinas de forma isolada. Isso é lamentável. (Cursista da 2a edição - Mulher)

Neste contexto, o 20 de Novembro é concebido enquanto data comemorativa, semelhante a outras como Festa Junina e Natal abordadas através da confecção de máscaras, cartazes, danças, degustação de pratos típicos, rodas de capoeira etc. Parece um arsenal alegórico aquilo que muitas escolas utilizam a fim de demonstrar o cumprimento de suas obrigações legais. Tais práticas evidenciam contextos escolares incapazes de se constituírem enquanto espaços pedagógicos que propiciam a valorização da identidade negra brasileira (Moura, 2005). Dessa forma, contribuem ativamente para a manutenção de sociedade e de um ensino de história que insiste em narrar sob perspectiva branca e europeizada. Tal visão abrange também a religiosidade, pois parte de uma lógica afroteofóbica (Jesus, 2003) e que omite as Africanidades Brasileiras. Vejamos um registro que exemplifica essa lógica:

A escola em que leciono à tarde e tenho uma turma de educação infantil é de filosofia luterana, não consigo desenvolver muita coisa. Lá, por exemplo, não pode ter apresentação de capoeira, por lembrar roda de batuque. Não me animo a levar nenhum instrumento musical de percussão ou chocalhos coloridos para não levar advertência. Então, minha sala em si não é um ambiente afirmativo. (Cursista da $1^{\mathrm{a}}$ edição - Mulher).

Além de sentir-se solitária em relação às iniciativas empreendidas, esta professora teme pelo seu emprego, dada a possibilidade de sanções administrativas. Nesta escola, uma roda de capoeira e o simples batucar de um tambor são capazes de despertar reações de pavor que transparecem preconceitos herdados de um pensamento ocidental e cristianocêntrico (SILVEIRA, 2014). Um pensamento imaginativo maligno (Silveira \& Custódio, 2017, p. 44) que, ao desconhecer os valores civilizatórios afro-brasileiros, equivocadamente os vincula com o culto ao diabo e/ou a demônios, figuras inexistentes para tais religiosidades que não estão ancoradas na crença dual que separa bem e mal. $\mathrm{O}$ trabalho que combate os binômios de mal e bem, civilizado e bárbaro, bonito e feio, atinge muitos dos registros feitos pelas docentes em observação. Ações 
pedagógicas com literatura infantil, brinquedos e brincadeiras, arte e música reiteram o desejo de superar o racismo com conhecimentos positivados das pessoas e comunidades negras.

Dispostas a se colocarem no lugar não só de quem ensina, mas de quem também aprende, algumas professoras se arriscaram no percurso em direção à promoção da igualdade racial.

Ao exporem suas dúvidas e inseguranças, nos presenteiam com lampejos de esperança que evidenciam o compromisso de saberem-se no mundo e, pensando o mesmo, desestabilizando-se a partir dos saberes emancipatórios construídos nas lutas do movimento negro educador (Gomes, 2017).

Estou muito empolgada e vejo que participar deste curso mudou meu modo de ver muitas coisas. Sinceramente eu só trabalhava atividades com leitura e escrita sobre cultura afro na Semana da Consciência Negra. Sempre vi como uma obrigação, assim como trabalhar outros assuntos que envolvem datas comemorativas. Agora vejo como pode ser prazeroso o conhecimento quando há um envolvimento tanto do professor quanto dos alunos. Eu também estou aprendendo muito! E não é só uma questão de teoria, estou mudando a minha prática e este é o maior ganho em fazer este curso! Vejo que é uma questão de respeito com a nossa história, com as nossas origens e, principalmente, com o aluno que precisa valorizar seus antepassados conhecendo na escola quem foram as pessoas de carne e osso que formaram nosso povo. Sair das enciclopédias que mostram através de modelos estereotipados a miscigenação e levar para dentro da sala de aula o que é real e palpável. (Cursista da 2a edição - Mulher)

Mas a desestabilização das subjetividades ocorre com mais resistências quando observamos que nos registros, as Africanidades Brasileiras foram abordadas tal qual um componente curricular do qual as crianças deveriam se apropriar, pouco direcionadas em sua dimensão de valores que transformam atitudes também das educadoras.

Ora essa apropriação teve a ver estritamente com conteúdos ensináveis (fatos históricos, pratos gastronômicos, estilos musicais, danças típicas, máscaras, localização geográfica, práticas religiosas, personalidades históricas e/ ou contemporâneas etc.). Ora com atitudes ensináveis (aprender a respeitar os negros, não dizer ofensas aos negros, não repetir ditados preconceituosos etc.). Ou seja, vezes alternadas entre conteúdos e atitudes. 
Todavia, seja em relação aos conteúdos, seja em relação às atitudes, destaca-se nesses registros o fato de que as professoras cursistas não se narraram enquanto sujeitos destas aprendizagens, pois suas ações estavam comprometidas com o ensino das crianças.

Em alguns relatos, eram evidentes as tentativas de exercícios da noção de alteridade, por meio dos quais as crianças deveriam aprender a se colocar no lugar do outro. Não exatamente de um outro que fosse negro, mas de um outro diferente. É interessante a operacionalização da noção de alteridade acionada por estas professoras: naturalmente as crianças brancas foram situadas como sendo a norma e tornaram-se a referência para os demais corpos, intitulados como diferentes. Também é digno de atenção a leitura do racismo como um tipo de discriminação que pode ser comparada a outra de qualquer natureza.

É como se as professoras cursistas tentassem suavizar a discussão, retirando da centralidade argumentativa o atributo da cor da pele e o igualando a outras características como, por exemplo, o sobrepeso. Interessante observar que se trata de uma tentativa de comparação entre algo que é considerado um problema de saúde - o sobrepeso - e uma propriedade fenotípica biologicamente normal - a cor da pele. Nesse tipo de analogia, subentende-se que a cor da pele (preta) passa a ser considerada também como um problema sobre o qual não se deve debochar. Vejamos um exemplo:

Expliquei que qualquer forma de preconceito é inaceitável, só que temos que nos dar conta que algumas vezes estamos reproduzindo ideias preconceituosas e chamamos isso de brincadeira. Disse que notava muito isso acontecer entre eles, que deveriam sempre se colocar no lugar do outro que está sendo agredido, insultado. Nesse momento uma aluna pediu a palavra e disse que não gostava quando a chamavam de gorda, que muitas vezes não tinha vontade de ir à escola por causa disso. Conversamos bastante sobre os apelidos e no final dois colegas pediram a palavra e pediram desculpa pra colega dizendo que não iam mais chamá-la de tal forma. Terminou a aula e disse que continuaríamos no outro dia a atividade. [...] O trabalho realizado com a turma foi muito significativo, pois deu oportunidade deles se colocarem e falarem coisas, brincadeiras, como eles chamam, que são feitas e desagradam alguns. Relatei o trabalho feito para os demais professores e assim como eu, notaram que pararam com os apelidos e estavam percebendo um maior respeito entre eles. (Cursista da $2^{\mathrm{a}}$ edição - Mulher) 
A abordagem que nega as especificidades do racismo e da discriminação racial como operadores de lugares de privilégio e positivação dos brancos, correlatos a espaços de negativação e menorização dos negros, é bastante polemizada no contexto da recepção das políticas curriculares de ERER e de ensino de História nos anos iniciais e educação infantil.

É como se apenas aos alunos - e não aos professores e demais adultos de referência - coubesse a tarefa de conhecer e respeitar as contribuições da população negra brasileira. O trecho a seguir é significativo:

Os alunos mostraram muito interesse em saber por que os negros saíam da África para serem escravos em diversos países. Eles queriam saber por que isso aconteceu. [...] Acredito que o objetivo principal foi atingido, que é desenvolver a consciência nos alunos do respeito e da valorização dos povos negros, da cultura africana e afro-brasileira na sociedade, destacando a importância dos mesmos na construção do povo brasileiro. (Cursista da $1^{\text {a }}$ edição - Mulher).

Essa percepção de "ensinar os alunos para que eles consigam..." é tão acentuada, que algumas professoras cursistas chegaram a registrar as expressões "missão e dever cumprido":

As máscaras africanas constituem sínteses de elementos simbólicos variados das vontades dos africanos, quem a carrega se sente protegido. [...] No final dos trabalhos eu e a professora X. nos sentimos com a missão e dever cumprido, pois todos os objetivos planejados, conseguimos realizá-los. (Cursista da $1^{\text {a }}$ edição - Mulher)

Tal reflexão não somente explicita o endereçamento do ensino a outros, como também o entendimento de que se trata de um processo concluso. Assim caracterizado é como se existisse um conjunto de conhecimentos a ser transmitido e, findo o repasse, é findo o processo. Como se as relações inter-raciais fossem submetidas a determinado protocolo que pudesse ser seguido ao pé da letra e não estivessem sujeitas à dinamicidade dos encontros e desencontros ao longo do percurso de cada um. Não é de se admirar que o ensino das Africanidades Brasileiras proposto nestes termos, por exemplo, não foge à reprodução do estereótipo de um povo que, ao ser chamado de africano, congregaria entendimentos unos e comuns. Tais registros pouco ultrapassam o ensino 
de História pautado na escravidão como experiência dos negros e não como violento projeto civilizador imposto pelos brancos, hoje considerado um dos maiores crimes de lesa-humanidade, ou seja, a escravidão em sua relação dimensional e inter-racial. Ficam as dúvidas: será que, no entendimento das crianças, onde há negros sempre há conflitos raciais? Será que o racismo e a discriminação racial presentes em nossa sociedade são tão acentuados ao ponto de impedir que consigam vislumbrar uma existência negra sem dor e sofrimento? Será que nós, adultos, somos capazes de vislumbrar essa existência?

Será que nos tornamos as vítimas perfeitas de, nas palavras de Kabenguele Munanga, um crime perfeito? E chegamos a nos sentirmos gratos e aliviados por não precisarmos falar sobre preconceito, discriminação racial e racismo? Como a professora cursista que considerou exitosa uma proposta pedagógica antirracista por meio da qual as crianças sequer foram capazes de dizer em voz alta que as pessoas retratadas nas imagens mostradas eram negras:

De modo geral as crianças conheciam os atores e a respeito das fotos fizeram comentários como: este lugar é de sair de férias; esta roupa é só de desfilar; quando crescer também quero jogar futebol. Percebi que o preconceito está mais no mundo dos adultos, as crianças mencionaram algumas particularidades, mas, de forma nenhuma a ridicularizar a imagem dos negros, a cor nem mesmo foi mencionada. (Cursista da 2a edição - Mulher)

Instiga-nos pensar que a ausência da nomeação dos negros possa ter sido considerada um elemento positivo, justamente em uma proposta que tinha por objetivo refletir acerca das relações inter-raciais. Novamente observamos a potência da invisibilização da população negra enquanto ferramenta de manutenção dos preconceitos e estereótipos raciais. Estamos falando não de uma inação, mas sim de expressiva ação de supressão de conjunto de conhecimentos e valores que poderiam e - mais do que isso - deveriam ser ensinados às crianças. Pois, se sequer mencionamos algo, não precisamos nos colocar em diálogo, nem em conflito.

Conflitos que algumas professoras cursistas tentaram tanto amenizar, que ao menos quiseram ou conseguiram relatar. Por vezes, registros comunicavam que qualquer pessoa pode obter sucesso e felicidade, independentemente de sua cor de pele, subentendendo que todos possuem as mesmas condições de competição e oportunidades. É uma prerrogativa a contribuir para a perpetu- 
ação do discurso meritocrático, que, dentre outras coisas, esmaga brutalmente toda e qualquer possibilidade de reflexão e discussão quanto à dimensão estrutural e estruturante do racismo em nossa sociedade.

\section{HorizONTE FINAL: DESAFIOS PARA A COMPREENSÃO}

DA DIMENSÃO RELACIONAL DO ENSINO DE HISTÓRIA AFRO-BRASILEIRA NOS ANOS INICIAIS E EDUCAÇÃO INFANTIL

Enfim, ao discorrermos sobre ensino e aprendizagem das Africanidades Brasileiras, estamos falando de conteúdo ou de atitudes?

Silva (2005) nos auxilia na resposta a esse questionamento:

Todo esse processo de aquisição de conhecimentos e de formação de atitude respeitosa de reconhecimento da participação e contribuição dos afro-brasileiros na sociedade brasileira requer que preconceitos e discriminações contra este grupo sejam abolidos, que sentimentos de superioridade e de inferioridade sejam superados, que novas formas de pessoas negras e não negras se relacionarem sejam estabelecidas. (Silva, 2005, p. 158)

Observemos, no excerto acima, a conjunção coordenativa aditiva "e". Ela está cumprindo a função de relacionar o "processo de aquisição de conhecimentos" à "formação de atitude respeitosa". Ou seja, evidencia o caráter complementar destas duas dimensões quando se está a ensinar - e aprender - as Africanidades Brasileiras, especificamente no tratamento do ensino de História nos anos iniciais e educação infantil.

Ainda, cabe destacar duas premissas apontadas pela autora. A primeira relaciona-se ao fato de não haver sinalização quanto à sobreposição de uma dimensão em relação a outra, pois ambas são tratadas com o mesmo caráter de importância. A segunda concerne aos sujeitos envolvidos neste processo de ensino-aprendizagem. Há, de um lado, alunos aos quais se deve ensinar variados conjuntos de conhecimentos e, também, atitudes de respeito e reconhecimento. Por outro aspecto, professores devem ser capazes de se colocarem no lugar de quem aprende, sendo esta aprendizagem visceralmente conectada ao compromisso com o enfrentamento dos próprios preconceitos e atos de discriminação, condição primeira para a organização de planos de aula ancorados 
em uma pedagogia antirracista. Falando de outro modo, é como se uma aula sobre a história da capoeira no Brasil pouco conecte com projeto educativo, caso o professor não seja capaz de reagir, por exemplo, a um colega que chama o outro de macaco no meio da explicação.

Ao analisarmos os registros anteriormente compartidos entre as duas dimensões apontadas por Silva (2005), de maneira que as distintas vivências ressaltadas nas subcategorias do núcleo de sentido Rupturas com o racismo compõem o espectro de aprendizagens pretendidas com o ensino das Africanidades Brasileiras, educação não é resultado, mas processo que incorpora procedimentos de desestabilização. No caso de uma educação concretizada em espaços escolares praticados numa sociedade racista e racializada, tais rupturas exigem formação para a Educação das Relações Étnico-Raciais.

Os relatos analisados evidenciam o posicionamento de poucas professoras enquanto reflexivas de si mesmas e de sua agência no contexto próximo, aqui pensado como escola de atuação. Reportamo-nos a professoras que se apropriaram do conceito de Africanidades Brasileiras de modo a proporem o ensino da história afro-brasileira a partir de uma abordagem pedagógica que buscou e encontrou algumas das contradições e complexidades profundas da trama histórico-social constituidora das dores e agruras acometidas aos brancos e negros deste país. Um enfoque que alcançou a dimensão relacional e atitudinal da ERER e ao qual não podem furtar-se professores comprometidos com o projeto de construção de uma sociedade justa, igual e equânime (DCNERER, 2004), inspirado em Valores Civilizatórios Afro-brasileiros.

Essas professoras foram protagonistas de dolorosos processos de autoconhecimento e tiveram de ficar ante a solidão, o desinteresse, o boicote e o desprezo dos colegas e gestores. Comportamentos - lamentavelmente - comuns em nossa sociedade quando estamos a tratar do preconceito, da discriminação racial e do racismo. Comportamentos que denunciam dores e sofrimentos - físicos, psíquicos e, sobretudo, coletivos. Por configurarem a sociedade do nosso país, são indicadores de uma proposição que nos é urgente e contemporânea, a de uma psicanálise brasileira, que segundo Kon (2017)

[...] teria o dever de desenterrar, de tirar de sob os escombros do recalcamento e da denegação, as marcas que instituíram nossa nação, facultando a narrativa das agruras específicas e singulares dessa história sempre atual, abrindo espaço para 
a reflexão e a metabolização das dores infligidas reiteradamente pela colonização, escravidão e exploração de nosso povo, desacomodando-nos do lugar de vítimas e de algozes, restituindo nossa potência ativa e integridade, valorizando toda e qualquer história pessoal em sua diversidade. (Kon, 2017, p. 27-28)

Importante considerarmos que, talvez, a metabolização de nossas dores, por mais necessária que seja, não tenha fôlego para nos mostrar que pessoas negras podem viver de outros modos, não necessariamente dolorosos e envoltos em sofrimento.

Relembrando relatos da surpresa das crianças ao descobrirem que os personagens felizes retratados num livro eram negros, destacamos que

[...] em uma sociedade racializada, como são todas as sociedades do Continente Americano e a maioria das sociedades do Planeta, a subestimação e a trivialização do racismo procedem de uma necessidade puramente ideológica. (Moore, 2007, p. 29)

Embora substancialmente relevantes, todas as sociedades do Continente Americano e a maioria do planeta, não são todas as sociedades do planeta. Quer dizer, uma proposta de educação antirracista que consiga contemplar a dimensão relacional e que seja capaz de buscar e apresentar às crianças estes alheios exemplos de sociedades não racializadas estaria também ensinando que um outro projeto de humanidade é possível. Afinal, não é só de dança, música, máscaras, pobreza e tristeza que vivem os negros do mundo! Urge ensinar a pluralidade da vida das pessoas e povos negros, contemplada a partir da positividade, com narrativas históricas acerca da multiplicidade existente em cada um/a de nós e nos grupos que constituem a humanidade. Estas histórias ensinadas, desde a educação infantil, aos pequeninos seres humanos, é de esperançar-se, conforme pretendia Paulo Freire (2018).

\section{REFERÊNCIAS}

BARDIN, Laurence. Análise de Conteúdo. São Paulo: Edições 70, 2011.

BENTO, Maria Aparecida da Silva. Branqueamento e branquitude no Brasil. In: CARONE, Iray; BENTO, Maria Aparecida Silva (org.). Psicologia social do racismo: 
estudos sobre branquitude e branqueamento no Brasil. Petrópolis: Vozes, 2002. p. 25-58.

BRASIL. Conselho Nacional de Educação. Parecer CNE/CP n. 003/2004 de 10 de Março de 2004. Diretrizes Curriculares Nacionais para a Educação das Relações Étnico-Raciais e para o Ensino de História e Cultura Afro-brasileira e Africana. Diário Oficial da União, Brasília, DF, 19 maio 2004.

CAVALLEIRO, Eliane dos Santos. Do silêncio do lar ao silêncio escolar: racismo, preconceito e discriminação na educação infantil. São Paulo: Contexto, 2017.

FREIRE, Paulo. Educação e Mudança. Rio de Janeiro: Paz e Terra, 2018.

GOMES, Nilma Lino. O Movimento Negro educador: saberes construídos nas lutas por emancipação. Petrópolis: Vozes, 2017.

HALL, Stuart. Cultura e Representação. Rio de Janeiro: Editora PUC-Rio: Apicuri, 2016.

GUATARRI, Félix. Caosmose: um novo paradigma estético. São Paulo: Editora 34, 1992.

JESUS, Jayro Pereira de. Terreiro e cidadania: um projeto de combate ao racismo cultural religioso afro e de implementação de ações sociais em comunidades-terreiros. In: NORÕES, Ciano (org.). Racismos Contemporâneos. Rio de Janeiro: Takano: Ashoka, 2003. p. 185-201.

KON, Noemi Moritz. À guisa de apresentação: por uma psicanálise brasileira. In: KON, Noemi; MORITZ, Abud; CURI, Cristiane; SILVA, Maria Lúcia da. (org.). O racismo e o negro no Brasil: questões para a psicanálise. São Paulo: Cortez, 2017.

MEINERZ, Carla Beatriz. Estereótipo. In: FERREIRA, Marieta de Moraes; OLIVEIRA, Margarida Dias de (org.). Dicionário de Ensino de História. Rio de Janeiro: FGV Editora, 2019. p. 102-106.

MOORE, Carlos. Racismo e Sociedade: novas bases epistemológicas para entender o racismo. Belo Horizonte: Mazza, 2007.

MOURA, Glória. O direito à diferença. In: MUNANGA, Kabenguele (org.). Superando o racismo na escola. Brasília: Ministério da Educação, Secretaria de Educação Continuada, Alfabetização e Diversidade, 2005. p. 20

NOGUERA, Fernando. Ubuntu como modo de existir: elementos gerais para uma ética afroperspectivista. Revista da Associação Brasileira de Pesquisadores Negros, Uberlândia, v. 3, n. 6, p. 147-150, 2011-2012.

SANTANA, Maria de Souza. Educação Infantil. In: Ministério da Educação/Secretaria de Educação Continuada, Alfabetização e Diversidade. Orientações e Ações para Educação das Relações Étnico-Raciais. Brasília: MEC/Secad, 2006.

SANTOS, Boaventura de Souza. Para uma pedagogia do conflito. In: SILVA, Luiz He- 
ron; AZEVEDO, José Clóvis de; SANTOS, Edmilson Santos dos. Novos mapas culturais, novas perspectivas educacionais. Porto Alegre: Sulina, 1996. p. 15-33.

SILVA, Petronilha Beatriz Gonçalves. Aprendizagem e Ensino das Africanidades Brasileiras. In: MUNANGA, Kabenguele (org.). Superando o racismo na escola. Brasília: Ministério da Educação, Secretaria de Educação Continuada, Alfabetização e Diversidade, 2005. p. 155-172.

SILVEIRA, Hendrix. Não somos filhos sem pais: história e teologia do Batuque do Rio Grande do Sul. 2014. Dissertação (Mestrado em Teologia) - Faculdades EST., São Leopoldo, 2014. p. 134.

SILVEIRA, Hendrix; CUSTÓDIO, Elivaldo. Combatendo a afroteofobia: argumentos jurídicos e teológicos para a defesa da sacralização de animais em ritos de matriz africana. Revista Labirinto, Porto Velho, v. 26, ano 17, jan./mar. 2017, p.35-54. Disponível em: https://bityli.com/5Gmuh Acesso em: 30-05-2020.

TRINDADE, Azoilda Loretto da. Valores Civilizatórios Afro-brasileiros e Educação Infantil: uma contribuição afro-brasileira. In: TRINDADE, Azoilda Loretto da; BRANDÃO, Ana Paula (org.). Modos de Brincar: caderno de atividades, saberes e fazeres. Rio de Janeiro: Fundação Roberto Marinho, 2010. (Coleção A Cor da Cultura, v. 5.).

Artigo recebido em 31 de julho de 2020. Aprovado em 16 de setembro de 2020. 